\title{
Temporomandibular joint dislocation due to acute propranolol intoxication
}

This article was published in the following Dove Press journal:

International Medical Case Reports Journal

I July 2010

Number of times this article has been viewed

\author{
Abbas Aghabiklooei' \\ Homan Elahi ${ }^{2}$ \\ Babak Mostafazadeh ${ }^{3}$ \\ 'Department of Medical Toxicology \\ and Forensic Medicine, Iran University \\ of Medical Sciences, Tehran, Iran; \\ ${ }^{2}$ Firouzgar Hospital, Department \\ of ENT, Tehran, Iran; ${ }^{3}$ Department \\ of Medical Toxicology and Forensic \\ Medicine, Shaheed Beheshty \\ University of Medical Sciences, Tehran, \\ Iran
}

Correspondence: Babak Mostafazadeh Medical Toxicology and Forensic Medicine, Shaheed Beheshty University of Medical Sciences, Loghman-Hakim Poison Hospital, Kamali Avenue, South Kargar Street, Tehran, Iran

Tel +982I 55409534

Email mstzbmd@sbmu.ac.ir

\begin{abstract}
Temporomandibular joint (TMJ) dislocation has not previously been reported as a complication of beta-blocker toxicity. We are reporting two cases of TMJ dislocation resulted from acute severe intoxication with pure propranolol (PPL) for the first time. Bilateral TMJ dislocation happened in two patients who were admitted to intensive care unit with diagnosis of severe acute PPL toxicity. Clinical diagnosis of TMJ dislocation was obtained by physical examination. Successful reduction was performed for both patients without subsequent recurrence in two weeks following hospital discharge. Both of our subjects had no previous history of lower jaw dislocation. There was not any risk factor for dislocation such as convulsion during admission period, recent face trauma, or oral manipulation by the medical team. This study showed that TMJ dislocation may occur after severe acute PPL toxicity probably due to spastic contraction of the lateral pterygoid muscle. This is against previously mentioned hypothesis that stated masseteric muscles contraction as the main cause of a bilateral dislocated TMJ.
\end{abstract}

Keywords: propranolol, toxicity, temporomandibular joint dislocation

\section{Introduction}

Severe spasm of the muscles that open and close the mouth, or stretch of the ligaments results in temporomandibular joint (TMJ) dislocation. ${ }^{1}$ In this condition condyle travels anteriorly along the articular eminence, becomes trapped in the anterior superior aspect of the eminence. Mouth closure would be prevented in this condition. Bilateral dislocation (symmetric type) occurs most often following extreme opening of the mouth during yawning, laughing, singing, or vomiting. ${ }^{2}$ It also results from dystonic reaction to some drugs. ${ }^{3}$ Mandible trauma can also lead to TMJ dislocation, that most often occurs unilaterally.

Dislocation is tremendously painful and makes the patient unable to close his/her mouth, is normally accompanied by excessive salivation. ${ }^{4}$

Acute propranolol (PPL) intoxication after suicidal attempt is not an uncommon clinical entity. Bradycardia, shock state, loss of consciousness, convulsion, and metabolic acidosis are the main clinical features of acute toxicity. ${ }^{5}$ Impending gangrene of extremities and exacerbation of Raynaud's phenomenon are also stated in the literature as the complications of PPL overdose. ${ }^{6}$

To the best of our knowledge, this is the first time that TMJ dislocation is demonstrated as a complication of PPL intoxication. 


\section{Case series}

\section{Case one}

A 26-year-old, recently divorced midwife suffering from anxiety, palpitation, and insomnia who received $40 \mathrm{mg}$ PPL daily was brought to emergency department (ED) due to ingestion of 90 tablets of $40 \mathrm{mg}$ PPL, 50 minute before admission. She received no other medications.

She developed severe bradycardia during physical examination (pulse rate [PR] 45/min) and was in shock state with blood pressure (BP) 75/40 mmHg, drowsiness, cyanotic skin, cool extremities, and weak radial pulses. Respiration examination was normal. After gastric lavage via nasogastric tube (NG tube) and administration of single dose activated charcoal, the patient was admitted to an intensive care unit (ICU) under cardiovascular monitoring.

The patient's laboratory data were as follows: Blood sugar $102 \mathrm{mg} / \mathrm{dL}$; Creatinine $1.3 \mathrm{mmol} / \mathrm{L} ; \mathrm{Na}^{+} 134 \mathrm{mEq} / \mathrm{L}$; $\mathrm{K}^{+} 3.4 \mathrm{mEq} / \mathrm{L}$; and $\mathrm{Ca}^{++} 8.6 \mathrm{mEq} / \mathrm{L}$. Arterial blood gas analysis showed $\mathrm{pH}$ 7.26; $\mathrm{PCO}_{2} 47 \mathrm{mmHg} ; \mathrm{PO}_{2} 76 \mathrm{mmHg}$; and total bicarbonate $13 \mathrm{mmol} / \mathrm{L}$.

Shock state and bradycardia was corrected at ICU, with administration of intravenous (IV) crystalloid fluid, dopamine and glucagon $(2 \mathrm{mg})$, and one vial of glucose hypertonic $50 \%+10 \mathrm{u}$ regular insulin $+\mathrm{KCl}$ as a gastrointestinal (GI) cocktail. Correction of metabolic acidosis was achieved by sodium bicarbonate IV $(88 \mathrm{mEq} / \mathrm{L})$.

After 16 hours, the patient was found with open mouth and face disfiguration. She was unable to close her mouth and showed excessive salivation. She had no pain or muscle spasms. Clinical diagnosis of bilateral TMJ dislocation was obtained by physical examination and was confirmed by radiography.

TMJ dislocation was reduced using the back and down maneuver without use of any muscle relaxant drug, such as benzodiazepine, before reduction. Post-reduction radiograph showed adequate reduction and had no subsequent recurrence two weeks following hospital discharge.

\section{Case two}

A 32-year-old man presented to the ED with obtundation two hours after ingestion of sixty PPL tablets $(40 \mathrm{mg})$. Vital signs at initial exam were BP $60 / 40 \mathrm{mmHg}$, PR 40/min/weak, and RR 12/min and he was in severe shock state. As gag and cough reflexes were intact, we did not attempt tracheal intubation. After initial gastric decontamination he received ringer lactate $(2.5 \mathrm{~L} \mathrm{IV})$ followed by atropine (1.5 mg IV). The patient was admitted to ICU due to sustained hypotension.
Initial $\mathrm{ABG}$ showed mild metabolic acidosis ( $\mathrm{pH}$ 7.32). Other laboratory data were: $\left.\mathrm{K}^{+} 5.1 \mathrm{mEq} / \mathrm{L}\right), \mathrm{Na}^{+} 138 \mathrm{mEq} / \mathrm{L}$, $\mathrm{Ca}^{++} 8.3 \mathrm{mEq} / \mathrm{L}$, blood sugar $98 \mathrm{mg} / \mathrm{dL}$, BUN 32 and creatinine $1.4 \mathrm{mmol} / \mathrm{L}$.

After 12 hours, the patient was unable to close his mouth. Bilateral TMJ dislocation was diagnosed by examination (face disfiguration, dropping of lower jaw, and depression in both side preauricular areas). Since dislocation was not caused by trauma, radiography was not requested for confirmation.

Reduction was performed successfully by the back and down maneuver without any muscle relaxant drug. Postreduction X-ray confirmed the treatment and he had no subsequent recurrence two weeks following hospital discharge.

\section{Discussion}

We describe two cases of acute pure PPL toxicity associated with bilateral TMJ dislocation as a complication. Dislocation was diagnosed by physical examination and was successfully treated by reduction without recurrence at two weeks follow-up.

Diagnosis of TMJ dislocation in PPL intoxicated patients was made clinically and required no further X-ray studies for diagnosis confirmation. Disfiguration of the patient's face and inability to close the mouth are the most important signs of this complication.

Bilateral TMJ dislocation in poisoned patients can result due to dystonic reactions to various drugs (metoclopramide and antipsychotics), extreme opening of mouth during yawning (similar to opioid withdrawal syndrome), attempts at tracheal intubations process, and vomiting after some acute drug toxicity or chemical poisoning. ${ }^{5,6}$ None of these risk factors were present in the two cases presented here. As well, neither patient had recent facial trauma secondary to loss of consciousness. We did not attempt tracheal intubation or orogastric tube to clear the stomach for either patient. There was no pain and no spasm of masticator muscles on palpation of the TMJ, conflicting with mechanisms of TMJ dislocation declared by earlier studies. $^{5-7}$

PPL has a topical anesthetic effect that may explain the absence of pain in these patients. Although PPL can increase release of the neurotransmitter acetylcholine at the neuromascular junction of skeletal muscle, we could not definitely verify dislocation of TMJ as a complication of severe acute PPL overdose.

Spastic contraction of the inferior lateral ptrygoid muscle due to unknown causes may be a main factor. The mechanism 
of PPL effect on masseter muscle must be assessed by future studies.

We have shown TMJ dislocation can occur in severe PPL toxicity. Considering this possible complication, physicians should avoid extreme opening of the patient's mouth; any attempt to tracheal intubation should be performed gently; and the physician should consider this complication when patient cannot close his/her mouth.

\section{Disclosure}

The authors report no conflicts of interest in this work.

\section{References}

1. Undt G, Kermer C, Piehslinger E, Rasse M. Treatment of recurrent mandibular dislocation, Part I: Leclerc blocking procedure. Int J Oral Maxillofac Surg. 1997;26:92-97.

2. Whiteman PJ, Pradel EC. Bilateral temporomandibular joint dislocation in a 10-month-old infant after vomiting. Pediatr Emerg Care. 2000;16:418-419.
3. Amsterdam, JT. Dental disorders. In: Emergency Medicine. Rosen D, Barkin R, editors. St Louis, MO: CV Mosby; 1998:2387.

4. Shorey CW, Campbell JH. Dislocation of the temporomandibular joint. Oral Surg Oral Med Oral Pathol Oral Radiol Endod. 2000;89:662-666.

5. Love JN, Howell JM, Litovitz TL. Acute beta blocker overdose: factors associated with the development of cardiovascular morbidity. $J$ Toxicol Clin Toxicol. 2000;38:275-281.

6. van Melle J. Beta-blockers and depression after myocardial infarction: a multicenter prospective study. J Am Coll Cardiol. 2006;48:2209-2214.

7. Kai S, Kai H, Nakayama E, et al. Clinical symptoms of open lock position of the condyle. Relation to anterior dislocation of the temporomandibular joint. Oral Surg Oral Med Oral Pathol. 1992;74:143-148.
International Medical Case Reports Journal

\section{Publish your work in this journal}

The International Medical Case Reports Journal is an international, peer-reviewed open-access journal publishing original case reports from all medical specialties. Previously unpublished medical posters are also accepted relating to any area of clinical or preclinical science. Submissions should not normally exceed 2,000 words or

Submit your manuscript here: http://www.dovepress.com/international-medical-case-reports-journal-journal

\section{Dovepress}

4 published pages including figures, diagrams and references. The manuscript management system is completely online and includes a very quick and fair peer-review system, which is all easy to use. Visit http://www.dovepress.com/testimonials.php to read real quotes from published authors. 